ORIGINAL RESEARCH ARTICLE

\title{
How a MOOC can effectively facilitate student transitions to an online distance postgraduate programme
}

\author{
Eva Kubincova ${ }^{\mathrm{a}, \mathrm{b}}$, Vicki H.M. Dale ${ }^{\mathrm{a}}$ and John Kerr ${ }^{\mathrm{b}, *}$ \\ ${ }^{a}$ College of Social Sciences, University of Glasgow, Glasgow, Scotland; \\ ${ }^{b}$ Learning Enhancement and Academic Development Service, University of Glasgow, Glasgow, \\ Scotland
}

(Received: 18 January 2018; final version received: 6 August 2018

\begin{abstract}
A Massive Open Online Course (MOOC) was developed to help promote awareness of, and support student transitions into, a fully online distance, credit-bearing postgraduate certificate (PGCert). A qualitative study using semi-structured interviews was undertaken with participants on the PGCert to investigate learner experiences of both the MOOC and PGCert, and to establish the extent to which the MOOC supported learners' transitions into the PGCert in terms of their (1) foundation knowledge, (2) study skills, (3) digital literacies, (4) readiness for selfdirected learning, and to determine whether additional efforts could have been directed to more effectively support student transitions. Findings revealed that the MOOC informed participants' decision to undertake the fully online PGCert, and that this was due to the effective learning design and a strong teacher presence throughout. The participants already possessed some background knowledge and a number of essential learning skills (though not uniformly), questioning assumptions around MOOCs as an aid to widening participation in higher education; however, the MOOC helped to enhance and unify these. Not surprisingly, there were some challenges encountered on entering online postgraduate study that the MOOC design could not anticipate or solve; therefore, we recommend that online learners are appropriately supported throughout their studies. This work has implications in terms of how MOOCs may help facilitate student transitions into other fully online, credit-bearing programmes of study.
\end{abstract}

Keywords: MOOCs; online learning; student transitions; teaching presence; learning design

\section{Introduction}

A Massive Open Online Course (MOOC) is an educational model that typically allows free access to online learning material to anyone who enrols. The term covers a spectrum of teaching and learning approaches, from primarily instructivist 'xMOOCs' to connectivist or constructivist 'cMOOCs' (Bayne and Ross 2014). Depending on the underpinning pedagogy, course activities range from those based on acquisition of information, such as watching video lectures and reading online articles, to actively

*Corresponding author. Email: john.kerr.2@glasgow.ac.uk 


\section{E. Kubincova et al.}

participating in forums, blogs and social media, as well as students being able to review their own and others' performance using quizzes and peer-reviewed assessments, respectively.

The emergence of MOOCs has stimulated debate about their value in higher education (Haggard et al. 2013). Stemming from their popularity, they are often viewed as a potential marketing strategy to enhance university reputation and boost enrolments onto paid programmes (Allen and Seaman 2014; Kerr et al. 2015) and attempts have been made to identify sustainable business models for MOOCs (Daniel, Vázquez Cano, and Gisbert Cervera 2015; Epelboin 2017). Reports suggest that the academic community welcome the positive disruption that MOOCs have brought to learning, with issues of access, flexibility and empowerment to broader socio-economic groups and geographical regions highlighted (Haggard et al. 2013; Wulf et al. 2014). However, rather than democratising education, some studies show that the majority of MOOC learners are young, well-educated and employed (Christensen et al. 2013; Dillahunt, Wang, and Teasley 2014; Emanuel 2013; Laurillard 2016). Stakeholders have also commented on the role of MOOCs as change agents embodying innovative pedagogies (Ferguson and Sharples 2014; Ossiannilsson, Altinay, and Altinay 2016). However, some commentators question the degree to which the pedagogical benefits of MOOCs are truly innovative (Armellini and Padilla Rodriguez 2016; Haggard et al. 2013).

MOOCs can help in harmonising different educational backgrounds of students (Daza, Makriyannis, and Rovira Riera 2013) and aid learners in confirming their choice of a subject (Vihavainen, Luukkainen, and Kurhila 2013), while learning online generally can help students acquire independence and self-discipline (Kirby et al. 2010). Study skills, digital literacies and a readiness for self-directed, independent learning are essential to student success and retention in online learning (Cross and Whitelock 2017; Muilenburg and Berge 2005; Rovai 2003). A few studies have investigated whether MOOCs help students effectively to transition into formal education. Daza et al. (2013) examined a MOOC on linear algebra, targeted at prospective university students who needed to complete a mathematical course as a part of their programme. Once accepted to university, students were satisfied with the MOOC as it gave them the opportunity to commence studies with comparable mathematical proficiency. Jiang et al. (2014) investigated a pre-university biology MOOC and found that a direct incentive in the form of early establishment of a major for underachieving students leads to higher completion rates of the MOOC by this group. Vihavainen et al. (2013) compared the academic achievement of two university cohorts: an exam-based intake and an intake based on a successful completion of Introductory Programming MOOC that was identical in content to the first programming course on campus. The MOOC cohort failed fewer courses and gained more credits than the exam-based cohort, and successful completion of the MOOC confirmed students' choice of study and aptitude for online learning.

Therefore, evidence exists that pre-course MOOCs can support student transitions to higher education. However, the MOOCs in all the aforementioned studies supported transitions to traditional face-to-face programmes. Our paper addresses a gap in the literature by investigating the role of a MOOC in facilitating student transitions to a fully online distance postgraduate programme. In particular, the study aimed to ascertain the extent to which participation in a MOOC had an impact on students' awareness of a fully online distance PGCert, and their preparedness in terms of (1) foundation knowledge, (2) study skills, (3) digital literacies and (4) readiness for selfdirected, independent learning. We also sought to investigate other aspects of the 
MOOC that supported the transition into the fully online distance learning PGCert. Finally, we identified ongoing challenges and implications for ongoing support for student transitions through online distance learning.

\section{Methodology}

\section{Context}

The Art Crime and Antiquities Trafficking MOOC provides the context for this study. The MOOC was hosted on FutureLearn ${ }^{1}$ due to the platform's pedagogical functionality, open nature and global reach. It was anticipated that this would also support learners' transition to a fully online distance Postgraduate Certificate in Art Crime and Antiquities Trafficking, offered by the University of Glasgow. Using Bayne and Ross (2014) as a reference, the MOOC is neither purely a cMOOC nor an XMOOC but a blend of predefined content as well as activities designed to promote peer-topeer interaction and generation of situational content. The embedded activities took advantage of FutureLearn's existing functionality such as the use of articles, video, quizzes and discussions to promote student engagement in an open learning community. These were organised using the $\mathrm{ABC}$ approach to learning design, which is later discussed in more detail (Perović and Young 2015). The first intake of students to the MOOC and associated programme was in 2016, with 10,960 learners enrolling in the first iteration of the MOOC, of which 5202 were active learners, of which 1,628 had a more than $90 \%$ completion rate, of which 30 enrolled on the PGCert.

\section{Methods}

Semi-structured interviews with individual PGCert participants were the primary method of data collection, as they allow a degree of standardisation of questions, enabling researchers to identify emerging patterns from the data, while allowing also participants to discuss issues of personal significance (Cohen and Crabtree 2006). The questions that were asked to participants, aligning with our research questions, are listed in Appendix 1, and may be summarised as follows:

- Experiences of the MOOC and PGCert to date, and the extent to which these met student expectations;

- Preparedness for the online PGCert in terms of (1) foundation knowledge, (2) study skills, (3) digital literacies and (4) readiness for self-directed learning, and the extent to which the MOOC assisted in the development of these and other skills;

- What could have been done differently to best support students transitions into the online PGCert; and

- Whether MOOCs should be an essential pre-requirement to learners undertaking fully online distance credit-bearing programmes.

Ethical approval to conduct the study was granted by the University of Glasgow's College of Social Sciences Ethics Committee (\#400160016). Participants were invited to contact the researchers confidentially via email in response to forum posts in the virtual learning environment (VLE), and participation was also encouraged by the programme lead during online teaching activities. Respondents were sent 


\section{E. Kubincova et al.}

a plain language statement, consent form and interview proforma in advance of participation. Data were transcribed by an independent professional company, and transcripts were reviewed for accuracy by the primary researcher (EK) before being thematically analysed (by authors EK and VHMD), using the approach advocated by Braun and Clarke (2006). A small number of participants, due to English being a second language, expressed a wish to respond to an interview proforma in their own time, which was emailed to the researchers. These and the interview transcripts were initially read through, and then read through again, with relevant text hand 'coded' electronically in MS Word. The third researcher (JK) independently handcoded a sample $(n=3)$ and then the researchers met to agree the approach to coding and discuss emerging themes. Codes were grouped into categories, and the researchers discussed the findings to agree on the overall 'themes' emerging from the data. Finally, as the writing of this article progressed, and as we revisited our original research questions and data, our narrative evolved to present an account of not only the benefits of the MOOC but also its limitations in terms of facilitating transitions to online distance learning. The final draft was sent to the MOOC/PGCert lecturer as well as the participants as a form of data validation to establish trustworthiness and credibility, also indicated by the inclusion of direct quotes (O'Brien, Harris, and Beckman 2014). The lecturer endorsed the report and added comments for clarification (e.g. in relation to student numbers, or clarifying where the participants must have been referring to their experiences of the MOOC or PGCert, if their accounts were ambiguous). Three student participants provided feedback that they too endorsed the report; one wanted us to highlight the importance of the Slack seminars in overcoming isolation as a distance learner; we therefore made a small change to address this point.

\section{Results}

Nine students agreed to participate (seven interviews and two emailed proformas). Thematic analysis revealed four key themes: the MOOC's role in stimulating enrolment onto the PGCert, the MOOCS role in enhancing student preparedness, enhancing student preparedness for online distance learning, the importance of the course instructor, and ongoing challenges and suggestions for improvement.

\section{The MOOC's role in stimulating enrolment for the PGCert}

The MOOC stimulated student enrolment on the PGCert by raising their awareness of its existence, enhancing motivation and confirming interest in the subject, and enabling students to develop self-efficacy in online learning.

\section{Awareness}

The MOOC was considered instrumental in raising participants' awareness of, and informed almost all participants' decisions to pursue, the PGCert:

... I know just from discussions in class it seems like many, if not all, of the students who applied that aren't already Glasgow students found out about it through the MOOC... (participant 4) 
Several learners were enticed into enrolment to formal study even if they had not previously thought about pursuing formal education in the area. This was partly due to the MOOC content:

I'm a writer ... I write a lot of murder mysteries so I'm just going to use that information for fiction but I would have gotten enough information for that just out of the MOOC but then when we had the section on antiquities theft that's what interested me enough to go for the PG certification. (participant 6)

The well-structured nature of the MOOC, in terms of the learning design, was also an incentive for students to learn more:

It was just so well presented and well done that I wanted to learn more and when I saw that there was a PGCert I decided that this was something I wanted to do. (participant 5)

\section{Motivation and confirming interest}

Some participants acknowledged that MOOCs in general provide a well-rounded overview into a topic and, by doing so, motivate their interest. Having a clear interest in this subject stimulated their intent to enrol on the PGCert:

This is something I'm so passionate about and also I worked so hard to afford; I really want to make the best of it now. I've got that motivation. (participant 3)

When asked if all online distance programs should have an associated MOOC, almost all participants agreed that it would be beneficial because it clarifies or solidifies the interest of the learner:

It's a good introduction because sometimes you'll approach a subject and you won't know if you're interested in it or not [...] So that gives you a good overview and it's a good enough introduction to whatever subject it is to make you decide whether you actually are interested or not. I think that will cut down on people enrolling for courses they had really misunderstood or misjudged or whatever. (participant 5)

\section{Self-efficacy}

Participation in the MOOC was seen to enhance self-efficacy by assuring learners that they possessed the necessary skills for learning successfully online. By completing the MOOC, learners were able to gauge their competencies and be more informed to decide if paid distance education was a viable investment:

I am fifty years old. So, I'm probably not in the average group of students. And I was in doubt if I [was] up to the task, to be able to study online. And the way the MOOC is structured, with the lectures and the chat with [the lecturer], and how she was asking questions and all of that; that encouraged me to say, okay, yes, I can do that. This PGCert is something that I'm qualified to tackle. (participant 1)

\section{Recognising the value of online learning}

The findings also revealed that a MOOC can improve learners' views of online learning in general and, in this way, encourage them to enrol to formal online studies. A few participants admitted that they were aware of various misconceptions about online 


\section{E. Kubincova et al.}

learning, or they went through a difficult experience themselves. However, from their point of view, a well-designed online course can be as successful as face-to-face instruction; the MOOC was influential in this realisation:

I hadn't studied online before and I'd had really bad experiences of ... like, really difficult online platforms. But the MOOC was a good example of how actually it can work quite nicely and it can be easy to share your ideas [...] Actually if it's done properly an online learning course can be just as good as a, sort of, in person thing. (participant 3)

\section{The MOOC's role in enhancing student preparedness for the PGCert}

One of the strongest and most prevalent messages was the fact that our participants represented a particularly knowledgeable group of students, most of whom either had academic or professional backgrounds close to crime, art history or antiquities. Nonetheless, while they possessed several pre-existing skills before embarking on the PGCert, most acknowledged that these were strengthened by participating in the MOOC.

\section{Foundation knowledge}

The MOOC played an invaluable role in providing concise yet comprehensive foundation knowledge. For many students, it consolidated pre-existing knowledge while introducing them to other foundation topics they were not familiar with:

I have a background in archaeology and heritage management so I'm aware of some of the issues that this course covers, but the MOOC gave me a good rounded introduction and had me thinking more about some of the areas that I wasn't so strong in. (participant 2)

In this respect, the MOOC had the capacity to unify students' prior knowledge, enabling them to join the PGCert with comparable knowledge:

...in a lot of ways the MOOC was very useful in kind of giving me, and certainly I think giving a lot of the other students, because they have mentioned it, a good kind of base level that we were all coming in at and I definitely think that, I think it makes for a stronger course, because everyone kind of has some background coming into it, it's not new information to people. (participant 4)

The MOOC was also seen to inspire interest in accessing additional reading before the start of the PGCert, further enhancing the prior knowledge of the students:

I started reading a lot of books before I started the [PG Cert] as well. I was able to either buy some books or access the local library and get some related to antiquities trafficking and do some background generic reading as well. (participant 2)

One student reported that this was enhanced by the availability of open access learning materials:

The MOOC had a strong focus on open access resources [...] I thought that was very useful in terms of kind of showing you where you could get things and even the fact that 
many of the things, you know, many of the articles and additional information you can dig into are located on the Trafficking Culture ${ }^{2}$ site. (participant 4)

\section{Digital literacies}

Participants generally demonstrated some experience in learning or working online; for example:

I don't see myself as a computer buff but I'm very active on Twitter, and I'm writing a shared blog [...] I'm normally online. (participant 7)

Despite this degree of confidence, results indicate that MOOC played an instrumental role in strengthening students' digital literacies. In our case, the MOOC was offered through the FutureLearn platform and the PGCert was run using the university's VLE (Moodle) and e-portfolio platform (Mahara). While these technologies differ, some students felt more at ease transitioning to the PGCert after having used the FutureLearn platform:

So, when I consider myself quite apt at working with technology, setting up all the systems, the Moodle and the Mahara and all the different systems in the University was for me more challenging than working with the MOOC. And so, the MOOC was a nice first step into getting ready to deal with this kind of online technology, specifically for learning. (participant 1)

\section{Study skills}

Most participants admitted to having well-established study skills prior to, or irrespective of, taking part in the MOOC. This was largely due to their academic background. A number of learners confessed to being avid readers and, therefore, did not have problems accessing set readings and critically engaging with them. Their academic experience had taught them the importance of reading as well as the skills of spoken and written critique or reflection:

I mean, personally for my undergraduate degree this was pretty much exactly the same thing as I would do. Sort of, look at set readings, do some more research on my areas of interest, read some more in that area and then collate my ideas. (participant 3)

Moreover, as one participant summarised, MOOCs are inherently accessible and less academically rigorous compared to credit-bearing programmes, which makes them less demanding:

Compared to what I've done before, the MOOC was actually relatively accessible in quite short periods of time, I probably spent two or three hours a week on it. It's not as relevant to those more, kind of, intense academic skills and obviously it's such an important part of the MOOC that it's accessible to people of all different, like, life stages and learning backgrounds. But just for me and my experience I think it was more using those skills already than, kind of, developing them further. (participant 3)

With more mature learners who had spent some time out of university, the general consensus was that the PGCert was well paced and, therefore, it was not overly problematic to refine their study skills as the programme progressed. 


\section{E. Kubincova et al.}

\section{Readiness for self-directed learning}

Similar findings were obtained with respect to self-directed learning readiness. Most of the students enrolled on the PGCert with well-established time management skills and self-motivation irrespective of the MOOC. Some participants admitted to being fairly autonomous, preferring to process the learning material by themselves and only then engage in discussion with peers. However, as one participant acknowledged, taking part in the MOOC highlighted the importance of managing their own time and taking responsibility for their own learning within an online course:

I think the most thing I learnt from the MOOC for the PGCert was that it's, you know, do it when you have the time and be able to more pick and choose what you want to elaborate on, give you a little bit more flexibility with what you want to get out of it, get out of the course, than being, you know, traditionally force-fed certain things. (participant 2)

Similarly, some participants commented on how the time-bound nature of the MOOC imposed pressure to maintain discipline in online studies, and in this way helped them to prepare for the more demanding academic environment of the PGCert:

The MOOC kind of shows you that [...] if you get behind, you know, if you take it easy and let yourself get behind, if you don't keep up with the reading things in the lectures then you're going to have to pay a price for it, so it's better not to get behind if you can possibly help it. (participant 6)

\section{The importance of the lecturer}

Participants suggested that the enthusiasm, presence and support of the course instructor helped them engage with online learning, and this was an important factor in their decision to enrol on the PGCert.

\section{Enthusiasm}

Many students commented on the lecturers' passion and enthusiasm for the subject, as well as their commitment to sharing knowledge:

The other thing that was really important about the MOOC in leading into the PGCert was that I saw short lectures by [the lecturer] and by other various members of staff and I was convinced obviously they were engaging and dedicated to teaching as well as to studying, because I've had some bad experiences before with academics who were obviously, like, world experts in their field but not as interested or, kind of, motivated to share their knowledge. (participant 3)

\section{Presence}

The presence of the lecturer was also seen to be crucial in terms of moderating online discussions, which kept students focused on the relevant information while simulating the face-to-face dialogue. Similarly, students appreciated the amount of information conveyed in the learning material, but welcomed the fact that if 
they wanted further information, the lecturer pointed them towards additional resources:

In the MOOC, I remember we could leave questions and then Donna would answer, or other students would come in, and then she would do a video session commenting on all the questions we'd done. This alternative to being in a classroom in person, interacting with the other students and with the lecturer, so I think this has been really great. (participant 1)

The use of the Slack chat platform for running live 'seminars' was also valued in terms of enabling distance learners to feel less isolated, as identified by one participant during the data validation phase:

I can corroborate your findings about the importance of the accessibility to the teacher AND the interactions among students and teacher. Just on Wednesday, on our last seminar on Slack I was telling [the lecturer] how important those seminars had been for me ... I remained sceptic as to how isolated I would be ... in a different time zone... the weekly seminars on Slack were my life-line to the academic environment ... The exchange of ideas among students and teacher ... was for me like water in a desert. (participant 1, participant validation comment)

\section{Support}

The tutor was also seen to offer a personalised approach to student learning needs:

For me, her guidance has been great because while she satisfies both aspects of my, let's call it, study personality. She gives us plenty of material to read and to satisfy our curiosity; and at the same time with the forums and the chat, she keeps us on track. (participant 1)

The tutor also helped students with technical difficulties. While few students reported that technical glitches occurred, the readily available support from the course instructor, and her supportive and caring manner, helped overcome these:

I think one other thing that is definitely important is just the level of helpfulness, I guess, or the level of concern that Dr Yates brings to this. Again, when I was having issues with getting some of the videos I got very quick responses from her and she was trying to help me and walk me through it, or even in the process of just applying to the PGCert and I had a number of questions about different things with it and, you know, she was very responsive and very helpful and I think, while in a perfect world I think all of the stuff would kind of be automated and you could kind of figure it out on your own, that's not the world we live in and I think it was both important and impressive at how responsive Dr Yates was. (participant 4)

Dr Yates was awarded a 'Best Online Learning Experience' Student Teaching Award in 2017 for her significant efforts.

\section{Challenges and suggestions for improvement}

The MOOC clearly played a role in enhancing student preparedness for the PGCert; however, there were areas where some students wanted to further strengthen their 


\section{E. Kubincova et al.}

knowledge base through engagement with more academically challenging content, or areas where they felt underprepared, such as academic writing, advanced study skills, technical challenges relating to university systems and English as a Second Language.

\section{More academically challenging content}

Although the MOOC covered the forefront of research, the learning materials were aimed predominantly at non-professional audience. To enhance the value of the MOOC in supporting the transition to an online PGCert, some students requested more challenging reading material in line with university-level readings:

I think if you were looking at it as a, kind of, precursor or prompt to start the PGCert then to me there's space for things to take more time and to be a bit more, kind of, academically challenging [...] I could certainly have [...] read more academic type sources, more journal articles and book chapters for example, even though there's obviously problems with sharing those, compared to case studies and press reports and stuff which are more factual. Like, I think more of the underlying theory could push it towards the, kind of, PGCert focus. (participant 3)

\section{Academic writing}

Learning activities on the MOOC that required academic writing skills consisted mainly of forum discussions, rather than written assignments. One student suggested opportunities to strengthen academic writing skills before joining the PGCert:

I think optional assignments, you know, mini, not quite essays but mini maybe questions and stuff does, sort of, prepare your mind for the fact that if you do this you will have to do more writing and it won't be passive and you'll have to do more thinking but I wouldn't go full-blown essay, maybe go, you know, maybe little pockets. (participant 5)

\section{Advanced study skills}

One student commented that their previous study had equipped them with study skills; however, the PGCert required a level of criticality they had not previously developed:

[Challenges] for me personally [were] just getting back into the mode of, like, you know, challenging sources, attacking the questions, looking at structures. That's something I've had to look at carefully, because there's not been any in the nature of my previous postgraduate study. (participant 3)

\section{Online study and communication skills}

It was pointed out that without the element of face-to-face interaction with peers it became difficult to gauge how much time to spend on online learning activities specifically. In this respect, including a time estimate for the learning tasks was considered to be beneficial:

For the description of the course, maybe add a time frame that would be needed each week. (participant 9) 
Another important finding was that the nature of online communication differed between the MOOC and the PGCert. This, however, was an easy transition due to the smaller cohort and supportive environment:

Because the other thing that wasn't so much part of the MOOC was interacting with the same people, you know, regularly. Because it was such a massive group you saw comments from people in reply to things, but it was just one-off interactions. But I feel I've been getting to know the other course participants and their areas of expertise which is really good $[\ldots]$ The peer marking and like, the sharing of our work. That helps with the, kind of, collaborative thing and it's just a good kind of supportive ethos. (participant 3)

However, one participant still struggled with the lack of face-to-face socialisation opportunities:

You're doing this remotely so it's very difficult to build up connections with people you've never met before. (participant 5)

\section{Technical challenges}

On entering the PGCert, some students - including those with digital literacies struggled with the technical aspects of institutional learning technologies and administrative systems, which the MOOC could not have prepared them for. These included officially registering with the university, submitting assessments online and accessing online library resources:

The Glasgow interface is very different from the MOOC one, so you have to navigate things differently and, you know, that took a bit of time to register with the university online and do everything. It was all quite straightforward but it took some getting used to, so maybe I wasn't quite prepared - the MOOC probably didn't prepare me that much for it. (participant 2)

Students reported that the technical forum helped but helpful responses were not immediate due to most participants focusing on the subject-focused forums, and additional written guidelines would have helped. However, one student commented on the value of the PGCert induction on learning online:

I was a little sceptical I guess in the introduction activities where it walked you through all the technologies [...] Why do we have to waste time on this? But I think it was actually very helpful and I've gone back and relooked at some of those things to try to understand [...] the online portfolio system. (participant 4)

\section{English as a Second Language}

One student commented that their lack of confidence in written English meant that they mainly tended to read other students' chat contributions on the PGCert, rather than post their own:

The vocabulary, I have so far collected 11 pages with words new or uncertain for me. I love the [chat] seminar but I still don't have the speed to really take part, I make some small comment but I'm pleased [to] be there and read the discussion. (participant 8) 


\section{E. Kubincova et al.}

\section{Discussion}

We reflect on our findings, particularly as they relate to the MOOC design and teacher presence, the emphasis on students' knowledge and skills, and the constructivist pedagogy underpinning the MOOC and PGCert. Although not used in the initial design phase, we have used Garrison's Community of Inquiry framework (Garrison, Anderson, and Archer 1999, 2010) as a lens through which to identify 'success' factors for enabling transitions to online distance learning, and as a basis for recommendations relating to good practice.

\section{Teaching presence}

Garrison and colleagues define teaching presence as relating to the instructional design of learning opportunities, and their facilitation, by the teacher. Here, we expand on the importance of effective learning design and teacher presence.

\section{Learning design}

Learners appreciated the MOOC, and the PGCert, for the way that learning activities were designed and structured. Despite different technical platforms for the MOOC (FutureLearn) and the PGCert (Moodle), learners reported a strong connection between both, including a level of continuity in the learning design. The authors (JK and VHD) advised the lead academic on course design and development. The courses were constructively aligned (Biggs 1999), with the academic encouraged to align the explicit intended-learning outcomes (ILOs) with assessment methods, and then design learning activities to support students' ability to demonstrate attainment of ILOs. The academic was advised to 'chunk' the content in line with good practice in online instructional design (Smith 2014). The ABC approach to learning design (Perović and Young 2015) was used to encourage the academic to engage learners using a variety of learning activities based on Laurillard's (2012) design science approach. It is therefore recommended that instructors looking to link a MOOC with credit-bearing online studies should consider using a similar approach to learning design.

\section{Role of the teacher in enthusing students and facilitating learning}

All interview participants referred to the presence, passion and personalised approach that the lead educator brought to the MOOC and the PGCert. We propose that teacher presence is vital to the success of a MOOC as an enabler to help students transition to a fully online, credit-bearing programme, and that this continues through the students' follow-on studies. There is some current thought that MOOCs can be delivered without teachers 'present' on the course, and that all facilitation can be done by peers. However, our study would negate this sentiment, and we would argue that for MOOCs to have the transformative effect this one appears to have done on encouraging learners to enrol on the PGCert, that teacher presence is vital. However, more research needs to be conducted in this area.

\section{Cognitive presence}

We interpret cognitive presence as involving what the students bring to the learning experience, and how they make sense of and apply their learning. For us, the study 
highlighted the importance of student motivation to learn, which was enhanced by the teaching presence. Cognitive presence, or the ability to make sense of and apply new ideas, is also dependent on students possessing the necessary skills to succeed in online learning. While most students possessed some of these, these were strengthened by engagement in the MOOC, which enhanced their self-efficacy for online learning.

\section{Motivation and enrolment}

The MOOC played a key role in confirming the learners' interest in the subject area, allowing them to feel confident that the experience they would get online would be of a high quality and comparable to the standard they would expect to get from a traditional face-to-face, on-campus degree. Importantly, having access to a MOOC beforehand helps learners to decide whether they are committed to the subject of the paid programme, and enhances their self-efficacy around online learning. Self-efficacy is highlighted as an important transition skill (Cheng et al. 2015). This should in theory therefore help address issues of retention in online distance learning (Simpson 2013).

\section{Pre-existing knowledge and skills}

In conducting this study, it became quickly clear that the majority of MOOC and PGCert participants were not traditional Masters students engaging in postgraduate study immediately after an undergraduate degree. They represented a range of experience and careers, and many of them took the MOOC and PGCert to enhance their careers. Participants brought pre-existing foundation knowledge and skills to the MOOC and PGCert; however, this was in particular fields of study rather than uniformly, and the MOOC helped to address this differential.

\section{Social presence}

Social presence relates to the ability of the learners to engage in peer discourse and communication, within a supportive, collaborative environment. The courses were designed using a primarily constructivist approach that strongly encouraged peer-topeer collaboration to support the links between theory and practice, given the diverse backgrounds of MOOC and PGCert participants. The live chat sessions were particularly valued by at least one participant in terms of overcoming potential isolation associated with distance learning (Duranton and Mason 2012). In terms of good practice, we would encourage practitioners, who are developing MOOCs as precursors to credit-bearing online programmes, to maximise the value of the presence of other learners to enable students to build a supportive community.

McAuley et al. (2010) describe the importance of learners developing their voice online, the ability to analyse, contribute and engage in active discourse in a massive, connected setting. Although the MOOC was underpinned by peer-topeer discourse, the massive nature of the community made it difficult to establish online relationships. However, this was less of an issue with the PGCert, as learners were able to get to know each other better. However, instructors should be mindful that while the nature of peer-to-peer interaction will change during the transition from MOOC to credit-bearing course, efforts are still required to facilitate effective collaboration. 


\section{E. Kubincova et al.}

\section{The need to continue supporting student transitions through online learning}

From the review of our findings, it is clear that the MOOC informed students' decision to enrol on the PGCert and that it helped to facilitate a successful transition to the PGCert by allowing participants to upskill their knowledge and skills in preparation for the credit-bearing programme. However, it is not possible for a MOOC, aimed at a general audience, to prepare students completely for a full online programme, and it is essential that students' transitions are not only supported into postgraduate online learning but also through postgraduate online learning. The need to support learners' transitions through blended learning (an optimal combination of face-toface and online learning) is highlighted by Adekola et al. (2017) and relates to the need to support student access, attitudes and attributes (skills) through appropriate student support and curriculum design.

\section{Limitations of the study}

This study was based on a single run of one MOOC and the initial run of a newly created online PGCert. This was a small qualitative study, with a limited number of participants; therefore, we make no attempt to generalise the study findings. It can therefore be considered to be an indicative case study with the potential to inform academic practice in terms of supporting learner transitions into fully online, creditbearing distance learning. In addition, we exclusively focused on the experiences of learners successfully enrolled on the PGCert rather than those who were unsuccessful or did not apply. In preparing this article, and through ongoing discussions of the findings, as well as revisiting our original research questions, our narrative evolved from one that reported the general outcomes of thematic analysis to one that tells a specific story of the potential for a MOOC to facilitate successful student transitions while recognising its limitations in this regard.

\section{Conclusions}

This study revealed that a MOOC, with a pedagogically informed learning design, accompanied by appropriate teacher presence, can facilitate learner transitions into a fully online distance learning programme of study. All the participants entered the MOOC with pre-existing knowledge and skills, again providing evidence against the primary role of MOOCs being for widening participation; however, these were not uniformly present. The MOOC helped learners' transition into the PGCert in terms of confirming their motivation to study online, consolidating and building on their prior knowledge and skills, and ensuring that these were of a uniform level pre-entry to the PGCert. We would recommend that future research should be undertaken in this area to further explore the potential of MOOCs in facilitating student transitions to online learning.

\section{Acknowledgements}

The authors would like to thank Dr Donna Yates, MOOC and Programme Director and Lecturer, who endorsed this study and encouraged participation from her students, whom they would also like to warmly thank for participating. They also thank 
the University of Glasgow for providing funding for the development of the MOOC and PGCert through the strategic Blended and Online Learning Development (BOLD) initiative.

\section{Notes}

1. https://www.futurelearn.com/courses/art-crime

2. http://traffickingculture.org/

\section{References}

Adekola, J., et al., (2017) 'Student transitions to blended learning; An institutional case study', Journal of Perspectives in Applied Academic Practice, vol. 5(2), pp. 58-65. doi:https://doi. org/10.14297/jpaap.v5i2.273

Allen, I. E. \& Seaman, J. (2014) Grade Change: Tracking Online Education in the United States. Available at: https://www.utc.edu/learn/pdfs/online/sloanc-report-2014.pdf

Armellini, A. \& Padilla Rodriguez, B. C. (2016) 'Are massive open online courses (MOOCs) pedagogically innovative?', Journal of Interactive Online Learning, vol. 14(1), pp. $17-28$.

Bayne, S. \& Ross, J. (2014) The Pedagogy of the Massive Open Online Course (MOOC): The UK View. Available at: https://www.heacademy.ac.uk/resources/detail/elt/the_pedagogy_ of_the_MOOC_UK_view

Biggs, J. B. (1999) Teaching for Quality Learning at University: What the Student Does. Society for Research into Higher Education, Open University Press, Buckingham.

Braun, V. \& Clarke, V. (2006) 'Using thematic analysis in psychology', Qualitative Research in Psychology, vol. 3(2), pp. 77-101. doi:http://dx.doi.org/10.1191/1478088706qp063oa

Cheng, M., et al., (2015) Transition Skills and Strategies: Self-efficacy. Enhancement Themes. vailable at: http://www.enhancementthemes.ac.uk/docs/publications/transitionskills-and-strategies---self-efficacy.pdf

Christensen, G., et al., (2013) The MOOC Phenomenon: Who Takes Massive Open Online Courses and Why? [Working paper]. Available at: https://www.openeducationeuropa.eu/ sites/default/files/asset/The $\% 20$ MOOC $\% 20$ Phenomenon.pdf

Cohen, D. \& Crabtree, B. (2006) Semi-Structured Interviews. Available at: http://www.qualres. org/HomeSemi-3629.html

Cross, S. \& Whitelock, D. (2017) 'Similarity and difference in fee-paying and no-fee learner expectations, interaction and reaction to learning in a massive open online course', Interactive Learning Environments, vol. 25(4), pp. 439-451. doi:http://dx.doi.org/doi:10.1080/ 10494820.2016.1138312

Daniel, J., Vázquez Cano, E. \& Gisbert Cervera, M. (2015) 'The future of MOOCs: adaptive learning or business model?', International Journal of Educational Technology in Higher Education, vol. 12(1), pp. 64-73. doi:10.7238/rusc.v12i1.2475

Daza, V., Makriyannis, N. \& Rovira Riera, C. (2013) 'MOOC attack: closing the gap between pre-university and university mathematics', Open Learning: The Journal of Open, Distance and e-Learning, vol. 28(3), pp. 227-238. doi:10.1080/02680513.2013.872558

Dillahunt, T. R., Wang, B. Z. \& Teasley, S. (2014) 'Democratizing higher education: exploring MOOC use among those who cannot afford a formal education', The International Review of Research in Open and Distance Learning, vol. 15(5). doi:10.19173/irrodl.v15i5.1841

Duranton, H. \& Mason, A. (2012) 'The loneliness of the long-distance learner: social networking and student support. A case study of the distance-learning MA in translation at Bristol University', Open Learning: The Journal of Open, Distance and e-Learning, vol. 27(1), pp. 81-87. doi:10.1080/02680513.2012.640790 


\section{E. Kubincova et al.}

Emanuel, E. J. (2013) 'Online education: MOOCs taken by educated few', Nature, vol. 503(7476), pp. 342-342. doi:10.1038/503342a

Epelboin, Y. (2017) 'MOOCs: a viable business model?', in Open Education: From OERs to MOOCs, eds M. Jemni, Kinshuk, \& M. K. Khribi, Springer, Berlin, Heidelberg, pp. 241-259.

Ferguson, R. \& Sharples, M. (2014) 'Innovative pedagogy at massive scale: teaching and learning in MOOCs', in Open Learning and Teaching in Educational Communities, vol. 8719, eds C. Rensing, S. de Freitas, T. Ley, \& P. Muñoz-Merino, Cham, Springer International Publishing, pp. 98-111.

Garrison, D. R., Anderson, T. \& Archer, W. (1999) 'Critical inquiry in a text-based environment: computer conferencing in higher education', The Internet and Higher Education, vol. 2(2), pp. 87-105. doi:https://doi.org/10.1016/S1096-7516(00)00016-6

Garrison, D. R., Anderson, T. \& Archer, W. (2010) 'The first decade of the community of inquiry framework: a retrospective', The Internet and Higher Education, vol. 13(1), pp. 5-9. doi:https://doi.org/10.1016/j.iheduc.2009.10.003

Haggard, S., et al., (2013) 'The maturing of the MOOC: literature review of massive open online courses and other forms of online distance learning', Department for Business, Innovation and Skills, UK Government.

Jiang, S., et al., (2014) 'Influence of incentives on performance in a pre-college biology MOOC', The international Review of Research in Open and Distributed Learning, 2014, vol. 15(5). doi:10.19173/irrodl.v15i5.1858

Kerr, J., Houston, S., Marks, L. \& Richford, A. (2015) Building and Executing MOOCs. A Practical Review of Glasgow's First Two MOOCs (Massive Open Online Courses), Project Report, University of Glasgow, Glasgow. Available at: http://eprints.gla.ac.uk/112764/

Kirby, D., et al., (2010) 'Graduates of the new learning environment: a follow-up study of high school distance e-learners', Quarterly Review of Distance Education, vol. 11(3), p. 161.

Laurillard, D. (2012) Teaching as a Design Science: Building Pedagogical Patterns for Learning and Technology, Routledge, New York.

Laurillard, D. (2016) 'The educational problem that MOOCs could solve: professional development for teachers of disadvantaged students', Research in Learning Technology, vol. 24(1), pp. 29369. doi:10.3402/rlt.v24.29369

McAuley, A., Stewart, B., Siemens, G. \& Cormier, D. (2010) The MOOC Model for Digital Practice, Available at: http://s3.amazonaws.com/academia.edu.documents/43171388/ MOOC_Final.pdf?AWSAccessKeyId=AKIAIWOWYYGZ2Y53UL3A\&Expires=15 00295358\&Signature $=$ pPCPeG12n9Cwypn YK7MwnZgujnY\%3D\&response-contentdisposition=inline $\% 3 \mathrm{~B} \% 20$ filename $\% 3$ DThe_MOOC_Model_for_Digital_Practice.pdf

Muilenburg, L. Y. \& Berge, Z. L. (2005) 'Student barriers to online learning: a factor analytic study', Distance Education, vol. 26(1), pp. 29-48. doi:10.1080/01587910500081269

O'Brien, B. C., Harris, I. B. \& Beckman, T. J. (2014) 'Standards for reporting qualitative research: asynthesis of recommendations', Academic Medicine, vol. 89(9), pp. 1245-1251. doi:10.1097/ACM.0000000000000388

Ossiannilsson, E., Altinay, F. \& Altinay, Z. (2016) 'MOOCs as change agents to boost innovation in higher education learning arenas', Education Sciences, vol. 6(3), p. 25. doi:https:// doi.org/10.3390/educsci6030025

Perović, N. \& Young, C. (2015) ABC (Arena Blended Connected) Curriculum Design, Available at: http://blogs.ucl.ac.uk/digital-education/2015/04/09/abc-arena-blendedconnected-curriculum-design/

Rovai, A. P. (2003) 'In search of higher persistence rates in distance education online programs', The Internet and Higher Education, vol. 6(1), pp. 1-16. doi:10.1016/S1096-7516(02)00158-6

Simpson, O. (2013) 'Student retention in distance education: are we failing our students?', Open Learning: The Journal of Open, Distance and e-Learning, vol. 28(2), pp. 105-119. doi:10.10 80/02680513.2013.847363

Smith, R. M. (2014) Conquering the Content: ABlueprint for Online Course Design and Development, Jossey-Bass, San Francisco. 
Vihavainen, A., Luukkainen, M. \& Kurhila, J. (2013) MOOC as Semester-Long Entrance Exam, Paper presented at the Proceedings of the 14th Annual ACM SIGITE Conference on Information Technology Education, New York, ACM, pp.177-182. doi: $10.1145 / 2512276.2512305$

Wulf, J., et al., (2014) 'Massive open online courses', Business \& Information Systems Engineering, vol. 6(2), pp. 111-114. doi:10.1007/s12599-014-0313-9 


\section{Appendix 1: Interview questions}

- Tell us your experiences of the MOOC and the PGCert so far.

- Have the courses met/not met/surpassed your expectations so far?

- In what way?

- What has worked well for you personally?

- What has been challenging?

- On hindsight, do you feel you were adequately prepared for the online PGCert in terms of your:

- Foundation knowledge of the subject

- Study skills

- Digital literacy skills

- Self-directed learning readiness

- Other skills required to be a successful online distance learner?

- To what extent were these skills developed specifically on the MOOC?

- What else has helped you to feel prepared?

- Is there anything we could have added to the MOOC, or any changes we could make, to have better prepared you for your online studies?

- What else could have been done differently to better support you for the online PGCert?

- From your own experience, should all online distance programmes have an associated MOOC? 